\title{
LA ESTÉTICA DE ORTEGA Y LA GENERACIÓN DE 1927
}

A Vicente Llorens

\begin{abstract}
Creemos estar trazando una y otra vez el esbozo de la naturaleza de la cosa, y lo único que hacemos es trazar alrededor el marco a través del cual la miramos.
\end{abstract}

WitTGenstein, Investigaciones filosóficas, I, núm. 114.

La circunspecta aplicación de la estética marxista a Galdós y a la generación del 98 por críticos como Antonio Regalado y Carlos Blanco Aguinaga nos ha dado una nueva perspectiva sobre el estudio de la prosa narrativa española, pero, en cambio, la crítica de la poesía española sigue siendo en conjunto un tanto formalista y neoretórica, lo cual es especialmente cierto en lo que se refiere a los estudios recientes sobre la generación de 1927. Como suele sucederles a las teorías de la autonomía del arte, esta crítica ha prestado muy poca atención al contexto histórico, con el resultado de que, mientras abundan excelentes lecturas de poemas aislados, las tentativas de una visión global de la generación apenas han hecho sino repetir la propia imagen histórica que la generación dio de sí misma.

El presente ensayo es un primer paso hacia una revisión de esa imagen histórica. Mi propósito es proporcionar un contexto histórico que nos ayude a una comprensión más exacta de la poética generacional de los poetas del 27. Esto, a su vez, debería abrir el camino a una lectura más exacta de la poesía, posible una vez que tengamos una idea clara de los presupuestos metafísicos que le sirvieron de base. Empezaremos por examinar la composición histórica de la generación, luego procederemos a una descripción parcial de la estética de Ortega (eje de nuestro contexto histórico), y por último sugeriremos una congruencia entre sus ideas y ciertas nociones sobre la poesía, defendidas por algunos miembros de la generación de 1927. 


\section{I}

Es curioso observar que cuando Salinas, Alonso y Cernuda hablan de una generación de 1927, los tres dejan traslucir la nítida impresión de que hubo en ella dos "momentos" más o menos distintos. Para el Salinas de 1940, hay un desarrollo ondulante en la poesía española entre 1900 y $1936^{1}$. Según él, la primera ola tiene su cresta en 1907, con las publicaciones poéticas de Unamuno y Manuel Machado. La segunda ola tiene su cresta en 1929, con la publicación del Primer romancero gitano de García Lorca, Cántico de Jorge Guillén, y los dos libros de Alberti, Cal y canto y Sobre los ángeles. La tercera ola, en opinión de Salinas, rompe en 1935 y está señalada por la publicación de La destrucción o el amor de Vicente Aleixandre, Premio Nacional de Literatura, para poesía, del año anterior, y de La realidad y el deseo de Luis Cernuda. Dámaso Alonso advierte una división similar en el interior de la generación, que corresponde a la hondonada entre la segunda y la tercera ola de Salinas. Habla Alonso de un neorromanticismo que dominó a sus coetáneos en los años 1929-1932. Escribe sobre los años precedentes:

... es cierto que en la poesía de 1920 a 1930 , por el afán de eliminar elementos seudopoéticos, no sólo se habían suprimido (según el ejemplo de J. R. Jiménez y A. Machado) los oropeles del modernismo (preponderancia del ritmo, vocabulario exótico y rico, decoración externa, etc.), sino que también se habían esquivado gran parte de las pasiones humanas o movimientos más directos de la voluntad (naturalmente que hablo sólo en términos generales) ${ }^{2}$.

Y menciona, como hitos en ese cambio, Espadas como labios (empezado en el verano de 1929) de Aleixandre, Poeta en Nueva York de Lorca, La voz a ti debida de Salinas y Soledades juntas de Altolaguirre. Podrían añadirse a su enumeración tres libros de Cernuda.

Este hiato en el interior de la generación, observado por ambos poetas-críticos, se hace doblemente importante cuando advertimos que corresponde a lo que podríamos llamar la reacción española al surrealismo francés. Es de notarse también que la aparición del surrealismo en España corresponde a grandes rasgos a un punto en que se produce un acontecimiento histórico-político cargado de significación en la historia española: el advenimiento de la Segunda República en 1931.

Aunque sin intentar una definición de lo que significa el surrealismo desde el punto de vista de la poesía española, puede decirse sin temor a la equivocación que el acercamiento al surrealismo

1 Penro Salinas, Literatura española, siglo $x x$, 2a ed., México, 1949, p. 38.

2 Dámaso Alonso, Poetas españoles contemporáneos, Madrid, 1952, p. 283. 
francés de Cernuda, Aleixandre, Alberti, Lorca y Prados fue un acontecimiento muy significativo. Angel del Río subraya especialmente la importancia del surrealismo en su estudio sobre Poeta en Nueva York, y recuerda que ya en 1925 Louis Aragon dio conferencias sobre este tema en la Residencia de Estudiantes donde vivía García Lorca. Si bien la visita de Aragon señaló la primera presentación del surrealismo en España, otros vehículos más asequibles de su influencia entre los miembros más jóvenes de la generación fueron Carmen (1927), donde Gerardo Diego publicó traducciones de los poemas franceses de Juan Larrea; Liloral, publicada en Málaga (1929) por José María Hinojosa, a quien Cernuda llama el primer surrealista español, y, en menor grado, Gallo: revista de Granada. Fue en Litoral donde Aleixandre publicó por primera vez algunos de los poemas reunidos más tarde en Espadas como labios, y donde Cernuda dio a conocer sus traducciones de Éluard. Hablando del surrealismo español, Cernuda dice de Larrea: "Al menos no creo equivocarme al pensar que a él le debieron Lorca y Alberti (y hasta Aleixandre) no sólo la noticia de una técnica nueva para ellos, sino también un rumbo poético que sin la lectura de Larrea dudo que hubiesen hallado"3. Y puesto que la poesía de Larrea apareció en cada uno de los siete números de Carmen, es difícil estar de acuerdo $\mathrm{C}_{\text {l }}$ estas palabras de D. Alonso (op. cit., p. 188): "Cuando Vicente Aleixandre, entre 1928 y 1929, escribe su Pasión de la tierra, del surréalisme francés lo ignora todo". Además de recordar la presentación de Aragon en la Residencia, Del Río confirma el punto de vista de Cernuda:

Hacia 1927 o 1929, dos años después de la conferencia de Aragon, se hablaba mucho de surrealismo entre las minorías de Madrid. Poetas como Juan Larrea y especialmente Alberti -amistoso rival de Lorca- habían dado los primeros pasos en la nueva senda. Era, además, el período de íntima amistad -casi de colaboración artísticaentre Lorca y Salvador Dalí, dirigentes de un grupo que contaba con Luis Buñuel, más tarde uno de los principales representantes del cine surrealista 4 .

Si nos volvemos ahora hacia el punto de vista de un poetacrítico más joven del mismo período, encontramos una insistencia más marcada aún en la división. Según Cernuda (op. cit., p. 193), la separación entre los miembros más jóvenes de la generación y los de más edad, Salinas y Guillén, es bastante visible. "En realidad -escribe-, tanto Salinas como Guillén, ni por su edad ni por su espíritu pertenecen a esta generación del 25". Por excéntrica que parezca esta opinión a la luz de los fuertes lazos de amistad que

3 Cernuds, Estudios sobre poesia española contemporánea, Madrid, 1957, p. 194.

4 ANGel Del Río, Poeta en Nueva York, Madrid, 1958, pp. 39-40. 
compartieron los miembros del grupo Guillén-Lorca, merece ser considerada con seriedad. No es sino una versión más aseverativa del punto de vista defendido por Alonso en su famoso ensayo. De hecho, si ponemos de lado el tinte de nostalgia y los lazos de amistad, cirugía claramente justificada por las exigencias del estudio, es claro que la generación del 27 es en realidad dos generaciones, la segunda de las cuales se desarrolla bajo la tutela de la primera y se aparta en los años 1928 a 1932, debido a la importancia de la influencia surrealista, no compartida por Salinas y Guillén, así como al advenimiento de la República, que son los acontecimientos literario e histórico que caracterizan al segundo y más joven grupo dentro de la doble generación. En esta perspectiva, el centenario de Góngora en 1927, que fue su primer y último acto de solidaridad, se convierte en un acontecimiento que induce a error si con él se designa a estos poetas. A modo de visión correctiva de la generación, Vicente Gaos menciona la posibilidad de llamarla la generación de la Revista de Occidente, si bien se pregunta si es efectivamente una generación en sentido riguroso. Pero esto desequilibra la balanza en el otro sentido, y, al no reconocer una división en la generación misma, lo que haría sería aplicar a la generación entera lo que sólo puede aplicarse a Salinas y Guillén. Sin embargo, sus observaciones tienen la virtud de poner en primer plano lo que ha sido ignorado o pasado por alto demasiado a menudo: que tanto Salinas como Guillén (y Dámaso Alonso) se movían en un mundo cuyos centros eran la Universidad de Madrid y el Centro de Estudios Históricos más que la Residencia, y donde los guías indiscutibles eran Menéndez Pidal y Ortega y Gasset.

A estas alturas, sólo confusión podría resultar de cualquier intento de cambiar el nombre de la generación Lorca-Guillén. Resulta más útil aceptar el término "generación del 27", a condición de que se tengan presentes ciertos hechos. Estos hechos son: 1) que el centenario de 1927, simbolizado por la fotografía tomada en el Ateneo de Sevilla, congela a los miembros de la generación en una pose un tanto artificial que no refleja la división visible ya en su poesía; 2) que las experiencias generacionales importantes fueron la llegada del surrealismo y el advenimiento de la República; y 3) que los dos miembros mayores del grupo, Salinas y Guillén, aunque estrechamente unidos por la amistad con los miembros más jóvenes, fueron sus mentores y modelos, pero no pudieron participar de esas dos experiencias generacionales de la misma manera que los poetas más jóvenes.

Esta revisión de su constitución no choca con las ideas actuales de los miembros más jóvenes de la generación del 27. En realidad, con la sustracción de Salinas y Guillén, la generación propiamente dicha ofrece una mayor homogeneidad de experiencia que antes. 
Pero coloca a los dos poetas mayores en un limbo. A menos, naturalmente, que aceptemos su posición como de figuras de transición (en opinión de Cernuda son una vanguardia) entre la generación de 1914 y la de 1927. Esta solución parece obvia, pero hasta ahora bien poco se ha hecho para delimitar las fronteras de la generación de $1914^{\circ}$. Y es preciso hacerlo previamente si queremos descubrir afinidades entre Salinas y Guillén y la generación precedente.

Hay varias razones para que los hispanistas hayan descuidado así a la generación de 1914. La primera es sin duda la magnitud de sus miembros y la variedad de sus disciplinas. Como lo ha señalado Juan Marichal, es la generación española más importante en el último siglo y medio, generación que incluyó gigantes como José Ortega y Gasset, Pablo Picasso, Juan Ramón Jiménez, Pablo Casals, Américo Castro, Gregorio Marañón, Pérez de Ayala, Gabriel Miró, Joan Miró, Ramón Gómez de la Serna, Rey Pastor, Blas Cabrera y Manuel Azaña. La segunda razón es que en gran medida el foco de su consenso fue antes político que artístico. En su mayoría eran, según la descripción de sí mismo que Azaña le dio a John Gunther en 1933, intelectuales, liberales y burgueses. Eran también especialistas que apenas compartían la mística de España de la generación del 98. En una palabra, eran una generación de intelectuales europeos que no veían ninguna incompatibilidad entre la acción política y las vocaciones que habían elegido.

Precisamente debido a su activismo político es fácil describir su período de ascendiente. Su primer acto público fue la formación de la Liga de Educación Política Española por Ortega y Azaña en 1913, seguida en mayo del año siguiente por la presentación pública de un programa, con la conferencia de Ortega titulada Vieja y nueva politica. Aunque años después habría de ser criticado en términos similares tanto por Azaña como por José Antonio Primo de Rivera por su inconstancia en política, era Ortega y no Azaña quien se encontraba en situación de presentar al público este programa. Profesional, psicológica y socialmente, estaba mejor preparado para aceptar la posición de guía que la prensa de Madrid le concedió tácitamente al reseñar su discurso del día anterior, que hacía época. Y Ortega siguió ejerciendo hasta cierto punto el caudillaje espiritual que había caído sobre sus hombros, pues con la publicación de las Meditaciones del "Quijote" en julio de 1914 y la aparición del primer volumen de El espectador a principios de 1916, quedó claro que Vieja y nueva política era nada menos

5 Juan Marichal ha desbrozado un nuevo terreno en esta área con sus penetrantes prólogos a las Obras completas de Manuel Azaña. Para lo que sigue estoy en deuda en parte con un resumen del primero de esos prólogos, aparecido en $I A L$, 1966, núms. 211/2, con el título de "La vocación de Azaña", así como con su ensayo "Persona y sociedad en la España moderna (1832-1936)", en El nuevo pensamiento politico español, México, 1966, pp. 103-118. 
que la piedra angular de un programa coordinado para hacer entrar a su país en el siglo xx. Pero para 1931 estaba claro que la guía política, si no intelectual, de su generación había pasado a Azaña. Es difícil decir si el retiro de Ortega de la política activa en esa época se hizo del todo a regañadientes. (Otros miembros de la Liga entraron en el gobierno con Azaña o sirvieron a la República en puestos diplomáticos). Pero debe recordarse que, además de ocupar la cátedra de Metafísica en la Universidad de Madrid, Ortega dirigía la Revista de Occidente, y desempeñaba al mismo tiempo muchas tareas editoriales. Además, desde la publicación de Sein und Zeit de Heidegger en 1927, Ortega se había visto obligado a reafirmar su propio estilo como filósofo y a revisar su propio desarrollo. Su serie de conferencias públicas de 1929 sobre el tema "¿Qué es filosofía?" es producto de esta revisión, y el hecho de que fuera un tour de force de filosofía "pura" sugiere que había tenido lugar una elección de prioridades.

Aunque Ortega había dejado de ejercer un papel activo en política desde 1931, su fortuna como intelectual y como ídolo de una nueva generación de escritores estaba inevitablemente ligada a la de los republicanos "moderados". Porque si Ortega había sido un guía a la vez político y literario antes de 1931, los miembros más jóvenes de la generación de 1927 estaban experimentando ahora una mezcla un tanto diferente de literatura y política. $\mathrm{Y}$ las dos ideologías, la nueva y la vieja, no podían oponerse de modo más dramático. Sin duda Ortega pensaba en la generación joven cuando escribió estas líneas en 1930: "Ahora, por lo visto, vuelven muchos hombres a sentir nostalgia de rebaño. Se entregan con pasión a lo que en ellos había de ovejas. Quieren marchar por la vida bien juntos, en ruta colectiva, lana contra lana y la cabeza caída". Tal era el origen del odio al liberalismo, según Ortega, porque "el liberalismo, antes que una cuestión de más o menos en política, es una idea radical de la vida: es creer que cada ser humano debe quedar franco para henchir su individual $e$ intransferible destino"'.

La llegada de la República se señaló por una pluralización más pronunciada de la vida intelectual de Madrid, y cada nueva manifestación era en parte una reacción ante el caudillaje de Ortega y una negación de él. A este respecto, la fundación de la revista católica Cruz y Raya por José Bergamín y Eugenio Ímaz en 1932, y de Octubre: escritores y artistas revolucionarios por Rafael Alberti en 1933 es sintomática. Los miembros más jóvenes de la generación de 1927 - Prados y Cernuda - se volvieron ahora hacia la revista de Alberti despreciando a la Revista de Desoriente,

6 Josḱ ORTEGa y GASSET, "Socialización del hombre", Obras completas, 6" ed., Madrid, 1962-1966, t. 2, p. 746. (Abreviaré en adelante O.C.). 
como la llamaba Juan Ramón Jiménez, mientras que Cruz y Raya abrió sus puertas a una nueva generación de poetas, amigos y discípulos de Xavier Zubiri, como Luis Rosales y Luis Felipe Vivanco. Pero incluso en 1929, cuando Ortega regresó de su segunda y mucho menos exitosa gira de conferencias por la Argentina, se encontró con que ya no podía atraer la admiración incondicional de poetas a los que había patrocinado al principio de los años 20 . El síntoma inicial de la rebelión es quizá el que apareció en el primer número de la aguda e irreverente Lola, dirigida por Gerardo Diego como suplemento de Carmen, que llevaba una "Letrilla", obra de su director, titulada "El espectorador y la saliva". Era un tributo, de todas formas, el que la rebelión de los jóvenes turcos tuviese que empezar con una andanada contra Ortega.

Hay motivos para suponer que Guillén y sobre todo Salinas se vieron atrapados entre dos fuegos literarios al principio de los años $30^{7}$. Es seguro que Salinas nunca hubiera apoyado los ataques humorísticos a Ortega ni mucho menos participado en ellos; pero al mismo tiempo su postura frente al filósofo había sido la de protector de esos mismos jóvenes poetas. Su relación con Ortega, por ejemplo, hizo que en 1925 se abrieran las puertas de la Revista de Occidente a los versos de Cernuda, que había sido alumno suyo. En el círculo de Ortega, Salinas se encontró colocado en el grupo de los jóvenes turcos, mientras que éstos, por su parte, lo veían cada vez más como a un miembro del Establishment. ¿Hasta qué punto tenían razón? Por supuesto, tanto Salinas como Guillén eran profesores, y el primero alto funcionario del Ministerio de Educación. Pero éstos no eran sino signos exteriores.

Lo que se ha descrito como el período de ascendiente de la generación de 1914 es en realidad el fondo contra el que debemos proyectar cualquier exposición completa e históricamente exacta de la llegada a la madurez de Salinas y Guillén. Mucho, aunque no lo suficiente, se ha escrito sobre sus contactos con la literatura francesa, concretamente con Proust y Valéry, pero se ha prestado poca atención a su primera formación intelectual en España, aparte de señalar, en el caso de Salinas, los resultados de sus lecturas de Machado, Unamuno y Juan Ramón Jiménez en su primer libro de poemas, Presagios $(1923)^{8}$. Pero Salinas era también, en igual medida, producto del Ateneo durante los años en que Ortega y Azaña echaban los cimientos de la República, y era también un joven erudito serio y discípulo de Menéndez Pidal en el Centro de Estudios Históricos. Aunque su amistad con Enrique Díez-

7 Sobre este particular véase la réplica intitulada "Carta a unos jóvenes independientes", en Juan José Domenchina, Crónicas de "Gerardo Rivera", Madrid, 1935, pp. 232-233, 236-239.

8 ANGEL DEL Río, "El poeta Pedro Salinas: vida y obra", en sus Estudios sobre literatura española contemporánea, Madrid, 1966, pp. 181-183. 
Canedo, poeta, ensayista y coeditor de una importante recopilación, La poesia francesa moderna (1913), asi como sus primeros poemas publicados en Prometeo en 1911 y sus lazos con el grupo de Ricardo Baeza, sugieren la imagen de un joven esteta ${ }^{9}$, es seguro que el realismo político del Ateneo hizo mella en Salinas. Un artículo del $A B C$ del 24 de marzo de 1914 sobre la Liga de Educación Política (debido tal vez a Azorín) incluye a Salinas entre los firmantes del Manifiesto, junto con Ortega y Gasset, Pérez de Ayala, Enrique de Mesa, García Martí, García Morente, Viñuales, Díez-Canedo, Federico de Onís, Azaña y Pittaluga. $Y$ al año siguiente, siendo lector de español en la Sorbona, Salinas dedicó un tiempo considerable a la traducción al español de tres libros de propaganda antigermánica ${ }^{10}$. Estos ejemplos sugieren, con justicia, que Salinas se movía con holgura en la orientación política de la generación de 1914, y que compartía sus preocupaciones nacionales e internacionales, tanto en lo académico como en lo político, lo cual ayuda a entender una faceta de su personalidad que incluso sus amigos podían difícilmente explicar: a saber, su papel como embajador de la cultura española. Ángel del Río se muestra sorprendido ante esa peculiar combinación de dúctil funcionario de asuntos culturales - Salinas era secretario-director de la Universidad Internacional de Santander- y poeta de la interioridad. Podría contestarse que Dámaso Alonso, Guillén y Cernuda fueron también profesores de literatura española en Inglaterra y Francia, pero existe una diferencia importante. Para Salinas los puestos de enseñanza en el extranjero, la instrucción de estudiantes extranjeros en España, la congregación de los mejores profesores españoles y europeos en Santander tenían la naturaleza de una respuesta personal al "problema nacional" de España frente a Europa que fue el legado de la generación del 98 a la generación de 1914. Al responder cómo lo hizo, hacía eco a las respuestas vocacionales de Ortega como filósofo y de Azaña como político. A esta luz, el enorme y paradójico enriquecimiento de la creatividad de Salinas después de 1936 puede verse como resultado de la confluencia de dos corrientes separadas de energía vital. Como si, en el exilio, el poeta hubiese descubierto en su poesía, sus ensayos y su teatro un lugar para la preocupación vital que se había expresado hasta entonces a través de su calidad de embajador cultural dentro de España.

Dejando aparte el temperamento, hay una marcada diferencia en la manera como Guillén se ubica en la corriente principal de las letras españolas. Sólo dos años menor que Salinas, su contacto con Francia -sucedió a Salinas en 1917 como lecteur d'espagnol en la Sorbona- tocó más de cerca el centro de su creatividad como

9 J. Marichal, "Pedro Salinas: la voz a la confianza debida", $R O c c, 9$ (1965), 159.

10 A. DEL Río, Estudios sobre lit. esp. contemporánea, p. 186. 
poeta. Salinas se había aclimatado a la literatura francesa mediante largas horas de lectura y de conversación en el Ateneo; para Guillén el cambio fue más abrupto. Salinas empezó a publicar poemas en 1911, mientras que Guillén, según ha declarado él mismo, empezó a escribir poesía en 1919, cuando estaba enseñando en la Sorbona. Su aclimatación fue tan completa y parte tan fundamental del hecho mismo de empezar a escribir poesía, que pudo elaborar una síntesis más completa de las preocupaciones vocacionales y nacionales que Salinas. Cuando en 1923 fue invitado a colaborar en un número que La Pluma dedicaba a Valle-Inclán, Guillén dio muestras de cómo su experiencia de la última poesía simbolista, específicamente de Mallarmé y Valéry, le había llevado a una posición desde la cual era imposible mirar atrás hacia la preocupación con España de la generación del 98. Pudo alabar a Valle-Inclán como al "poeta puro de la generación de 1898" precisamente a causa de las blancas páginas mallarmeanas que éste no había cubierto con el problema de España, pero eso fue todo. Y aun esta desmayada alabanza "literaria", se ofrecía desde el punto de vista de la generación de Ortega:

Oh, aquel terrible nacionalismo a redropelo de aquellos demoledores del '98. Basta, basta. Necesito ser real como un europeo cualquiera. No me place, hipotético, sentirme perdido, egregiamente perdido en la irrealidad de una España demasiado planteada como problema... ¿No es bastante vivir simple y fuertemente - sin más- esta tremenda y magnífica fatalidad de ser español?11

Guillén revela también una afinidad espiritual con Salinas y con la generación de 1914 cuando reconoce que ser europeo y español es algo que no tiene forzosamente por qué colocar al artista creador en un dilema -el de unir, antes que oponer, lo español y lo europeo- si los términos en que se plantea son los suyos propios. Guillén será un poeta español, pero deberá permitírsele igualmente que naturalice sus propios modelos.

En todo caso, tanto Salinas como Guillén debieron darse cuenta pronto, cuando empezaron a frecuentar las oficinas de la Revista de Occidente, y a medida que su familiaridad con Ortega aumentaba, de que el filósofo había enfrentado y resuelto aquel mismo dilema en 1913, con la redacción de las Meditaciones del "Quijote". Quizá lo que los empujó hacia Ortega fue precisamente darse cuenta de que él había dado una solución filosófica a un problema nacional, de que lo había descontaminado, es decir, había mostrado que se lo podía tratar de un modo profesional y vocacional más que personal (unamuniano). Tal vez se sentían muy a gusto p. 70 .

11 Jorge Guiltén, "Valle-Inclán y el '98", La Pluma, núm. 32 (enero de 1923), 
en la atmósfera cosmopolita de la Revista de Occidente. En todo caso, ambos se ligaron a la revista de Ortega y ambos, por su presencia en la tertulia de éste, se hallaron en una posición privilegiada para observar de primera mano la evolución de su filosofía.

Es significativo que Salinas y Guillén compartieran esta posición durante el período que marca $s u$ ascendiente sobre los miembros más jóvenes de la generación de 1927. Se trata de la época que va más o menos de 1923 a 1930 y que la mayoría de los críticos y de los participantes miran retrospectivamente como una especie de aberración: la época de la "poesía pura" y de la "deshumanización del arte". Pero conviene no hacer caso de las connotaciones peyorativas que adquirieron estos términos, y fijar nuestra atención sobre dos puntos: 1) que en España Salinas y Guillén fueron en parte responsables, debido a su posición de guías, de lo que esos términos pretendían originalmente describir, fuera ello lo que fuera, y 2) que durante esa época estuvieron en contacto estrecho con Ortega. La lectura de las Meditaciones del "Quijote" y otros ensayos "literarios" de Ortega, junto con la de Presagios, Seguro azar y Fábula y signo, y los Cánticos de 1928 y 1936, sugiere que la atención tanto de Salinas como de Guillén se veía atraída no sólo hacia ciertos temas -automóviles, elegancia, el Escorial-, sino hacia una nueva visión de la poesía, obra del filósofo en desarrollo. De modo que esa amistad de los dos poetas con Ortega durante aquellos años debería llevarnos a preguntarnos si no hay alguna afinidad entre el programa filosófico de Ortega y el período Salinas-Guillén de la doble generación del 27.

Si tenemos razón en suponer 1) que Salinas y Guillén deben verse como avanzada y como los mentores de la generación del 27 propiamente dicha, y 2) que su madurez como poetas tuvo lugar bajo la égida de la generación de 1914 y en estrecho contacto con Ortega, entonces debemos mirar con más atención el contexto cultural en que nació su poesía. Se ha escrito bastante sobre el papel de Menéndez Pidal como director del Centro de Estudios Históricos, donde Salinas ocupó un puesto administrativo, pero se ha escrito extraordinariamente poco sobre la capitanía paralela de Ortega en el campo de la filosofía; es decir, nada que sea pertinente para la historia literaria del periodo. $\mathrm{Y}$ sin embargo, mientras $\mathrm{Me}$ néndez Pidal reunía a su alrededor a figuras como Américo Castro, Federico de Onís y Navarro Tomás, Ortega, que había sustituido a Salmerón en la cátedra de Metafísica de la Universidad de Madrid en 1910, constituyó un equipo comparable de filósofos, y jun- 
tos realizaron un segundo milagro. Cuando Ortega regresó de Marburgo se le consideraba neokantiano. Pero en 1913, el año en que escribió las Meditaciones del "Quijote", la fenomenología hacía sentir su presencia fuera de Alemania con la publicación de las Ideas de Husserl y de la Ética de Max Scheler en el Jahrbuch der Phänomenologie. Y al mismo tiempo, bajo la dirección de Ortega, empezaba en España lo que Spiegelberg ha llamado una "asombrosa naturalización"12. En poco tiempo Madrid se convirtió en uno de los centros pioneros de estudios fenomenológicos en Europa. Desde 1913 o 1915 hasta fines de los años 20 los filósofos más estimados fueron Brentano, Husserl, Scheler y Hartmann. José Gaos, que llegó de Valencia para completar su grado en 1921, esperaba estudiar con neokantianos, pero en lugar de eso, como él mismo recuerda, "me encontré con que Morente se puso a dedicar un día a la semana a explicar la fenomenología de Husserl, porque era la última palabra a que había que atender..." $\mathrm{Y}$ así, durante una década Gaos se alimentó de una síntesis de fenomenología realista como verdadera y única filosofía ${ }^{13}$. A esta distancia en el tiempo, podríamos sentirnos tentados a pensar que la experiencia de la fenomenología de Gaos no fue más que una experiencia académica de un joven filósofo, una experiencia que no pasó de las salas de conferencias universitarias. Nada más alejado de la realidad. Ortega era a la vez un esteta, un metafísico y un pensador político, y su entusiasmo por Husserl y Scheler se hacía sentir no sólo en la Facultad de Filosofía y Letras de San Bernardo, sino también en el Ateneo, en la Residencia de Estudiantes y en el Centro de Estudios Históricos.

Si se ha escrito poco hasta ahora sobre la extensión de este interés en la fenomenología, se debe a que quienes más han hecho en el período de postguerra para asegurar y defender la posición de Ortega en España han restado importancia a la influencia de esta corriente en su desarrollo filosófico. De tal modo que el lector casual es alentado a aceptar sin más examen la pretensión de Ortega de que en 1931 había rebasado el idealismo de las Ideas de Husserl y dejado atrás la fenomenología. De hecho Ortega reaccionaba entonces frente a Husserl como Sartre y Merleau-Ponty lo harían unos veinticinco años más tarde. Pero si Ortega fue uno de los primeros en reaccionar contra el "giro subjetivo" de Husserl, no debe utilizarse ese hecho para negar lo que fue, desde un punto de vista cultural, uno de los ingredientes importantes en la vida intelectual española de aquella época: a saber, el hecho de que de 1913 a 1929, Ortega fue considerado como un exponente hasta

12 Herbert Spiegelberg, The phenomenological movement, The Hague, 1960 , t. 2 , p. 612 .

13 Jośt Gaos, Confesiones profesionales, México, 1958, p. 33. 
cierto punto crítico de la fenomenología y reputado en España y Argentina como fenomenólogo de una clase superior. Más aún: en ningún sitio está este hecho más abundantemente documentado que en la rama de la filosofía que precisamente es de esperarse que atraiga a los escritores y críticos más jóvenes: en los numerosos ensayos de Ortega sobre estética y arte. Una vez que se ha tomado un poco la medida del espectro de Husserl en estos ensayos, debería ser fácil mostrar que Salinas, Guillén y sus contemporáneos no dejaban de darse cuenta de lo que Ortega estaba haciendo.

Afortunadamente, no tenemos que ocuparnos aquí de una descripción completa de la estética de Ortega. En cambio, quisiera centrarme en los escritos de Ortega de los primeros años de su ascendiente, aproximadamente el breve período que va de 1909 a 1914. Y esto por tres razones: primera, porque éstos son los años del encuentro de Ortega con la fenomenología y de su modificación; segunda, porque es en este primer período cuando la estética de Ortega toma forma; y tercera, porque nuestro interés primario es el de describir aquella parte de su estética que ofrece lo que podríamos llamar una epistemología para poetas. Este último punto exigirá una explicación extensa, porque es, en mi opinión, la clave del atractivo de Ortega sobre los poetas españoles.

Todos hemos notado la brecha ideológica romántica que hubo entre España y los otros centros literarios de Europa, pero nadie ha sugerido nunca ninguna relación entre esta indigencia de teoría literaria romántica en España y la predilección de la generación de 1927 por Góngora. Veamos qué luz puede arrojar esta relación sobre la dinámica en que se ha desenvuelto la poesía española moderna. En la superficie, como es sabido, la poesía española de la segunda y tercera décadas de este siglo se desarrolla de una manera no muy diferente de la de la poesía angloamericana. Debido a la lectura de Bergson por T. E. Hulmes, hay en esta última tradición una insistencia similar en la imagen, que conduce por un lado al imagism, y por otro a un nuevo interés en los poetas metafísicos. Pero ciertos críticos agudos del período moderno, principalmente Kermode y Langbaum, han sostenido que el objetivismo y la impersonalidad de este período no son sino un desarrollo lógico de la estética simbolista que, a su vez, prolonga la manera enajenada del romanticismo. Si tal punto de vista es correcto, en lugar de buscar el análogo español del romanticismo inglés, alemán y francés, los hispanistas harían mejor en descubrir los efectos de la ausencia de tal análogo en la poesía española moderna. Porque si Espronceda tuvo que dirigirse a Edward Young en busca de un lenguaje de percepción poética y Juan Ramón Jiménez se vio obligado a escoger a Shelley para ese mismo fin, fue simplemente porque el romanticismo español no había desarrollado ni adoptado 
una manera de enfrentarse poéticamente a la naturaleza y a la mente del poeta, esos Gemelos de la teoría y la práctica románticas, según Wellek y de Man. Claro que hubo exaltación en la España romántica, pero no de la imaginación poética como potencia creadora y correspondiente. En cuanto a la teoría de la naturaleza (el otro gemelo) sólo ha habido dos, y ninguna de ellas tiene nada que ver con el período romántico: la primera es neoplatónica, la segunda una combinación de Schopenhauer y del determinismo biológico del siglo xIx. En la época moderna aparecen, separadas o mezcladas, en escritores como Baroja, Neruda y Dámaso Alonso. Pero en ningún caso se puede hablar seriamente de panteísmo. Esto es así porque después de Garcilaso la ortodoxia española parece haber rechazado, junto con el humanismo erasmista, las doctrinas herméticas que se desarrollaron dentro del neoplatonismo y que se convirtieron en fuentes de la búsqueda protocientífica del Renacimiento ${ }^{14}$. Así, pues, España estuvo privada de una importante tradición literaria europea: la noción de una naturaleza animada por el espíritu y acorde con lo humano, que corre subterráneamente en el siglo xviII y emerge de nuevo en el resto de Europa con el romanticismo ${ }^{15}$. De tal manera que, en lugar de una naturaleza que envuelve a un espíritu que a su vez informa a la mente humana, la literatura española, después de Góngora, describe una naturaleza caída y opaca. Como lo ha sugerido Elias Rivers (art. cit., p. 260): "Estamos, de hecho, más cerca de la realidad exterior deshumanizada recientemente descrita por Robbe-Grillet, según el cual vivimos no en un mundo de espejos humanísticos, sino frente a objetos duros, secos, remotos, que sóio pueden verse desde fuera".

El resultado de esta visión del mundo es que dejó al escritor en sus elevadas regiones metafísicas, y lo dejó, además, sin ese importante legado romántico que es el lenguaje de la poética. En lugar de ser un vidente romántico, un profeta que traspasa el velo de las apariencias, el español se convirtió en un artífice, un artesano que "entra a saco libremente en una natura naturata sin alma en busca de los cabos y retazos que son necesarios" para crear algo que no puede considerar sino como ficciones provisionales y tímidas (Rıvers, p. 261). Por eso las imágenes españolas son recursos retóricos y no símbolos en el sentido romántico-simbolista del término. Si el mundo es todo superficie, no hay razón para utilizar, como lo hace el simbolista, emblemas y análogos de un más allá invisible y "real". El mundo es simplemente el mundo: no hay más allá. $Y$ por eso Góngora, el maestro del artificio, vino a

14 Elias L. Rivers, "Nature, art and science in Renaissance poetry", $B H S, 44$ (1967), p. 262.

15 Margaret Gilman, The idea of poetry in France, Cambridge, Mass,, 1958, p. 135. 
quedar tan cercano a la generación de 1927. En la literatura española, las consecuencias metafísicas han sido cercenadas. Hay el poeta, y hay el mundo, y eso es todo lo que hay. En resumen, pues, hay una especie de visión del mundo implícita que se ha desarrollado en la literatura española a falta de las teorías románticas. $\mathrm{Y}$, como lo hemos visto, difícilmente puede equivaler a una epistemología para poetas.

Ni será tampoco de ninguna utilidad intentar hacer de la generación del 98 una excepción en esta tradición literaria del "mundo caído". Unamuno parece romántico porque reacciona enérgicamente, no ante un universo newtoniano impersonal, sino ante la antiespiritual filosofía de la naturaleza que profesa la ciencia de fines del siglo xIx. Por una parte saquea a Sénancour, por la otra intenta hacer de la identidad del yo el centro y la fuente de todos los valores. Esto último sería romántico si la idea del yo no estuviera a su vez en crisis. $\mathrm{Y}$ esta crisis del yo no es romántica, sino moderna. Sin embargo, Unamuno fue un defensor tan ardiente de los valores románticos de la espontaneidad, la sinceridad y el yo, que provocó una fuerte reacción en Ortega y Gasset. Contra Unamuno, y en nombre de una nueva objetividad y de la tradición española del "mundo caído", el joven Ortega, aun antes de su encuentro con Husserl, quería volver la atención de los españoles hacia "las cosas mismas". Tal vez sea ésta la razón de que el nombre de Velázquez aparezca casi infaliblemente cada vez que Ortega encara la cuestión del "realismo" español. "La emoción española ante el mundo -escribe Ortega en "Arte de este mundo y del otro" (O. C., t. 1, p. 200) - no es miedo, ni es jocunda admiración, ni es fugitivo desdén que se aparta de lo real, es de agresión y desafío hacia todo lo suprasensible y afirmación malgré tout de las cosas pequeñas, momentáneas, míseras, desconsideradas, insignificantes, groseras". Pero decir que no había dioses, como Ortega pensaba que decía Velázquez, era también afirmar que "las cosas no tienen, además de su constitución material, el aroma, el nimbo de una significación ideal, de un sentido. Es decir que la vida no tiene sentido, que las cosas carecen de conexión" (O.C., t. 2, p. 58). De este modo Ortega iniciaba la búsqueda de un kosmos noetós, y empezaba también a desarrollar lo que acabaría siendo en las $M e$ ditaciones una epistemología y una justificación para poetas. Pero Ortega había tropezado con el dilema de alcanzar la objetividad y al mismo tiempo dotar de "sentido" y "conexión" a las "cosas", sin referencia a la subjetividad. En este punto de su desarrollo parecía que no hubiese adónde volverse sino a Platón, que es lo que hizo Ortega en su ensayo sobre Renan de 1909. Aquí las verdaderas realidades, las verdaderas cosas, son impersonales, universales, y su universalidad es una ley del universo. Por eso los 
verdaderos clásicos, los hombres de genio son los que mantienen su yo en suspenso y descubren en el universo una nueva ley:

Platón descubre el origen de la ciencia en este amor, este Eros, este afán de contemplar las cosas en sí mismas, y no en los juegos de placer y dolor que dentro de nosotros producen. En la Consti. tución civil o República pone al amante de la verdad -filósofoformando una clase especial dentro del linaje de los curiosos -filotheamones-, de los amigos de mirar, y cuando busca un nombre expresivo para la ciencia no logra hallar otro más exacto que "teoría", visión, contemplación (O. C., t. 1, p. 448).

Estos "amigos de mirar" -Newton, Leibniz, Cervantes, Velázquez y Buda-son, literalmente, los creadores del suelo metafórico de presupuestos sobre el que nos apoyamos. Ortega estaba a punto de encontrar, si es que no lo había hecho ya, la confirmación de este punto en la "doctrina del sentido" de Husserl ${ }^{16}$. El ensayo sobre Renan es importante, pues, por varias razones: primeramente, muestra a Ortega al borde de una respuesta husserliana a la posición pararromántica de Unamuno; y en segundo lugar, sitúa al artista a la par del científico, respondiendo por los mismos consonantes a la crítica de Platón contra los poetas. Pero en 1909 no hay todavía ninguna indicación de algo que no fue enunciado claramente hasta el "Ensayo de estética a manera de prólogo", de 1914: a saber, la importante distinción orteguiana entre "ejecutividad" e "imagen", entre "conciencia primaria" y "consciencia". Ahora bien, si esta distinción es fundamental para la filosofía del perspectivismo y de la razón vital de Ortega, es el meollo mismo de su pensamiento sobre estética. Además, al desarrollar las consecuencias de su distinción, Ortega ofrecía a los poetas españoles una justificación casi metafísica de sus pretensiones, dando al mundo caído y opaco una profundidad, una nueva hondura, sin dividirlo en fenómenos y nóumenos. En lugar de hablar de la apariencia, hablaría de sentido e interpretación. En lugar de una realidad oculta más allá, describiría la realidad muda e insignificante que está simplemente ahí, pero que reclama interpretación. Así, tal vez ya desde 1909, pero sin duda en 1914 y con la publicación de las Meditaciones, Ortega había desarrollado a la vez una teoría general de la realidad, en consonancia con la visión del "mundo caído" de la naturaleza en la literatura española, y un medio de abordar esa realidad.

Por supuesto, además de los ensayos sobre temas literarios, hubo

16 Si Ortega no había leído las Investigaciones lógicas de Husserl cuando escribió su ensayo sobre Renan, es extraordinario lo cerca que se encuentra su "teoría de la verosimilitud" del terreno de las "unidades ideales" de Husserl. Ortega no alude expresamente a la "doctrina del sentido" de Husserl hasta 1916. 
también otros trabajos técnicos que tocaban a la fenomenología y que dieron a conocer el nombre de Husserl más allá de los confines de la Universidad. Aunque a menudo de naturaleza meramente expositiva, es sin embargo a esos ensayos a los que hay que volverse para encontrar indicios de la reacción de Ortega ante Husserl. Para dar un solo ejemplo, en el ensayo "Sensación, construcción e intuición", Ortega aparece una vez más preocupado, como en el ensayo sobre Renan, por descubrir un medio para el conocimiento verdadero y objetivo. "Se trata - dice- de hallar una función cognoscitiva que por su carácter, no en virtud de extrínsecas garantías, dé a sus contenidos inmediatamente el valor de verdades. . . Y llamamos ser, verdad, objetividad, al correlato genérico de esa función, a su contenido genuino, a lo que mediante ella captamos"' ${ }^{17}$. Ni el empirismo radical (Mach y Ziehen) ni el idealismo crítico de Cohen y Natorp pueden proporcionar este conocimiento inmediato. Sólo en la intuición directa de las esencias husserlianas, parece decir Ortega en otro ensayo, es posible este conocimiento. Ello se debe a que "en toda intuición individual puede abstraerse de este elemento que individualiza y convierte en hecho al objeto quedando sólo éste, insumiso a narraciones tiempo-espaciales, invariable, eterno"18. Ésta es la pura descripción de las esencias, sólo posible una vez que la "actitud natural" de Husserl ha sido puesta entre paréntesis. Sin embargo, no bien terminó Ortega de considerar la epoché de Husserl cuando se dio cuenta de que era autodestructora. De modo similar al de Sartre y Merleau-Ponty años más tarde, encontró que la conciencia pura de Husserl hacía de sus objetos un espectro, reduciéndolos a la mera inteligibilidad. En una palabra, Husserl seguía estando en la corriente central del idealismo cartesiano. Por consiguiente, a juicio de Ortega, el verdadero logro de Husserl era su descripción de la "actitud natural" y no las reducciones fenomenológicas. Para Husserl, después de 1913, la conciencia se convirtió en la conciencia pura; para Ortega no era ni independiente, ni absoluta, ni primaria. Más bien, la comprobación fundamental a su respecto era que "para ella nada es sólo objeto, sino que todo es realidad"19. De este modo sorteaba Ortega el giro subjetivo de las Ideas de Husserl de 1913. Pero al hacerlo estaba negando también que pueda haber un conocimiento inmediato, en cuanto opuesto a la intuición, de los hombres o de las cosas. Si el "milagro" de la epoché no podía producirse, el hombre estaba "encerrado" no en la cárcel de la conciencia sino en la realidad viva de la vida no reflexiva - lo que Ortega llama "ejecutividad" en el "Ensayo de estética a manera de prólogo" de

17 ORTEGa y Gasset, Apuntes sobre el pensamiento, Madrid, 1959, p. 102.

18 ORTEGA Y GASSET, "Sobre el concepto de sensación", O.C., t. 1, p. 252.

19 Ortega y Gasset, Prólogo para alemanes, 2" ed. (Taurus), Madrid, 1961, p. 68. 
1914. Esta "ejecutividad" o intención mundana, que es la única interioridad que existe, no puede nunca ser un objeto para los demás o incluso para nosotros mismos, porque no es sino la manera de ser-en-el-mundo de cada sujeto, y cuando nos volvemos para reflexionar sobre ella, ya no está allí. Esto equivale a decir que todas las cosas poseen una opacidad constitutiva; que nosotros mismos somos opacos; que tenemos que tratar con el mundo a través de interpretaciones, conceptos del mundo. Sólo en el arte -escribe Ortega en este ensayo- alcanzamos lo que parece ser un conocimiento inmediato de esta "interioridad" de las cosas. Pero no es la de Ortega una teoría expresiva del arte. Como él mismo aclara en el ensayo a que nos referimos, el arte no puede ser nunca un vehículo para comunicar a otros lo que fluye en nuestro subsuelo espiritual. Y esto es así porque nuestra subjetividad, nuestra propia identidad, no es una "cosa" en absoluto; existe únicamente como nuestra "ejecutividad", nuestra conciencia primaria de las cosas, las gentes, las ideas. En la medida en que podemos conocerla, es siempre una imagen que vemos mirando hacia atrás. En el resto del ensayo, Ortega habla de la metáfora como de la forma más simple del objeto estético. En nuestra experiencia de la metáfora, dos objetos de conciencia reales quedan ligados tan estrechamente que se aniquilan mutuamente como objetos reales. El primer paso en el ejemplo de Ortega es la conexión de un ciprés y una llama. Debido a que su identidad absoluta es inconcebible, nos vemos forzados a ir más allá de ellos para encontrar esta identidad en un objeto nuevo, un ciprés ideal que podemos ver como una llama.

Pueden sacarse importantes conclusiones de esta descripción de "ejecutividad" y metáfora, y Ortega las saca todas explícitamente. En primer lugar, el lenguaje descriptivo no hace sino utilizar imágenes-signos para expresar otras imágenes -cosas, sentimientos, personas, ideas-, mientras que el arte utiliza nuestros propios sentimientos "ejecutivos" como vehículo y puede así dar la ilusión de la "ejecutividad". Las palabras sólo hacen gestos en la dirección de las cosas, mientras que el arte muestra lo que sería estar dentro de ellas. En segundo lugar, el arte es esencialmente irrealización; el objeto artístico es un nuevo objeto ideal que no es ni de carácter psicológico ni de carácter físico, y contiene, como uno de sus elementos, "la trituración de la realidad". Y en tercer lugar, debido a que la irrealización sólo puede alcanzarse si el artista opta por el lado noético o referente al árbol, Ortega puede decir además que cada poeta añade una nueva creación al universo, riquezas que no son nunca superadas como lo son las del científico. Esto no es decir que lo que el poeta exhibe es su corazón, sino más bien su manera peculiar de entender el mundo; el estilo es el hombre, pero de una nueva manera. 
Sería imposible comentar una obra de la complejidad de las Meditaciones del "Quijote" tan brevemente como hemos tratado de hacerlo con este ensayo más temprano sobre estética, y tal vez no es necesario. El principio que hay detrás de obras tardías como La deshumanización del arte y Notas sobre la novela -la "ejecutividad"- está ya elaborado, como hemos visto. Pero podemos por lo menos aludir sumariamente a las Meditaciones. Debería ser claro a estas alturas que su aforismo central - "yo soy yo y mis circunstancias"- está relacionado por todas partes con la "ejecutividad" que Ortega desarrolló a partir de la "actitud natural" de Husserl. Y en las Meditaciones ésta es la realidad primaria; es lo que es la vida humana. Pero aquí, para no verse aplastado por el avance de la cruda realidad caída, el hombre lucha por interpretar, por dar sentido, por hacer de las obtusas superficies un mundo. De tal manera que Don Quijote se convierte, en su búsqueda interpretativa, extractora de logos, en el emblema de todos nosotros; y es igualmente la encarnación viva de una epistemología para poetas, como pronto habría de ver Pedro Salinas. Su ver es un mirar; una visión activa, no pasiva, que levanta la realidad "caída". En lugar de ser un "impresionista", como lo son a menudo los realistas españoles, Don Quijote descubre activamente, libera del olvido los sentidos latentes de las cosas "caídas". Casi podría decirse que Don Quijote es un héroe de la Razón vital, y en un sentido es verdad. Ciertamente no es un idealista romántico para el modo de pensar de Ortega. Más bien es como el científico y especialmente como el poeta, que acrecienta nuestra cosecha de realidad. Como ellos, es un héroe de la Imaginación, esa suprema expresión de la libertad del hombre, pues lucha por hacer su obra en un mundo que no está ni cargado ni desnudo de sentido, sino que simplemente está ahí: una presencia bruta, resistente, que debe ser superada.

Es claro que en este brevísimo esquema de la estética de Ortega he dado una visión menos que satisfactoria. Pero es porque he intentado únicamente destacar, sin caricatura, algunos de los aspectos que me parecen de interés en relación con Salinas, Guillén y otros.

\section{III}

No hay duda de que los escritos sobre estética de Ortega constituyen una contribución original que no sufre desmedro por su manera circunstancial de presentarse. Tampoco hay para qué discutir si esos escritos estuvieron o no al alcance de los poetas para su uso. Lo que sí queda por mostrar es hasta qué punto tuvieron un efecto real en los poetas y críticos de la generación del 27. No es éste el lugar de examinar en detalle su poesía. Pero puede ser ilu- 
minador sugerir al menos la dirección que tal estudio podría tomar, observando el lenguaje crítico con que Salinas y Guillén aprecian a Góngora y con que su propia poesía es valorada por sus contemporáneos. Góngora, mascota de la generación, tiene que ser una piedra de toque reveladora. He aquí lo que dice Salinas:

El secreto de Góngora está en que no reproduce la realidad tal como se le muestra ante los ojos, en sus líneas y dimensiones normales, sino que la agranda, la exalta como pocos poetas lo han hecho. ¿Por qué? Recordemos que la realidad es para Góngora su tema, su objeto poético. Pero la realidad tal como es ¿puede ser objeto poético? Para Góngora, no. Bajo su concepción poética parece haber un principio fundamental que yo formularía así: la insuficiencia poética de la realidad. La pura, la cruda realidad no es suficientemente poética, nunca tiene realmente carácter poético... ¿Qué hay que hacer para convertirla en poesía? Elevarla, intensificar sus características a un grado extremo, exaltarla por encima de sus formas naturales y extraer de éstas todo su contenido estético por medio de la imaginación y la fantasía.

Y un poco después, en la misma conferencia: "A fuerza de ser exaltada, elevada a valor estético, la realidad desaparece, queda pulverizada, perdida. Góngora, que quiere tanto a la realidad y que quiere ver sus cosas hermosas, la suprime, la destruye. ¿Para qué? Para darnos otra realidad, creada poéticamente con realidad verdadera"

Ahora escuchemos a Guillén. Nótese que aunque él escribe teniendo en la mente un interés distinto del de Salinas, sus apreciaciones siguen cayendo netamente dentro del círculo descrito por los puntos de vista estéticos de Ortega. He aquí la primera apreciación: "Góngora, ya lo sabemos, es un entusiasta del orbe material, y el alma se concentra en los cinco sentidos: propensión hacia cuanto ahínca una resistencia que es menester gozosamente conquistar". Y he aquí la segunda: "Mientras tanto, es la inteligencia con los sentidos quien tiende una red de relaciones entre los objetos sensibles... Las afinidades entre el agua, la piel de Galatea y el cristal, afinidades efectivas, han sido descubiertos por los ojos y la razón o, más bien, por los ojos de la razón"²1.

No pueden separarse las ideas expresadas aquí del lenguaje en que están acuñadas; es simplemente inconcebible que Ortega, en

20 Pedro Salinas, Reality and the poet in Spanish poetry, reed. de Baltimore, 1966, pp. 139-140, 145.

21 Jorge Gurlé́n, Lenguaje y poesia, Madrid, 1962, pp. 57 y 61. Véase OrtegA y Gasser, Meditaciones del "Quijote", ed. con comentarios de Julián Marías, 2 " ed., Madrid, 1966, p. 99. La expresión "red de relaciones" se encuentra en la página anotada, junto con importantes informaciones que deberían ser de interés para los estudiosos de Guillén. Compárense esos pasajes con "Plaỵa (Niños)", del primer Cántico. 
muchos casos, sea responsable tan sólo de las palabras que de hecho se emplearon. Debemos más bien reconocer la parte de Ortega y admitir que él preparó una posición estética desde la cual por lo menos dos miembros de la generación del 27 pudieron examinar y estimar la poesía de Góngora. Si las pruebas precedentes no son lo bastante persuasivas, veamos lo que otros críticos contemporáneos tienen que decir. Porque, a juzgar por lo que han escrito Ángel del Río y Amado Alonso, respectivamente, sobre Salinas y Guillén, como amigos y como críticos eran perfectamente conscientes de la relación entre la nueva poesía y el movimiento fenomenológico en España. Escuchemos a Angel del Río hablando de Salinas y la realidad: "Poeta de su tiempo, la realidad para Salinas tiene un sentido que pudiéramos llamar fenomenológico. Está fuera, existe, pero al poeta sólo le sirve para aspirar a recoger su esencia invariable mediante una serie de percepciones" ${ }^{\prime 2}$. No nos sorprenderá que Amado Alonso diga algo muy parecido sobre Guillén. Después de citar las estrofas descriptivas de dos poemas del primer Cántico, comenta: "Y tenemos entonces la poetización de documentaciones o descripción artística, meta de tantos poetas excelentes. Pero esto sólo es en Guillén el trampolín para el gran salto de la creación. Su poesía aspira a algo más que a vestir con plumas de colibrí o de pavo real todos los pajarracos de la realidad. No quiere encubrir; descubrir, desvestir el objeto de sus propiedades transitorias -existenciales, diría un fenomenólogopara sorprender su secreto sentido, su alma escondida: su estructura, su esencia" 23 .

Estas citas son el más escueto muestreo, pero no puede negarse su importancia. Tomadas juntas (y hay no pocas que son iguales), recuerdan muchas de las áreas principales de lo que se considera generalmente como la poética de la generación del 27. Todos estos elementos -la suspensión del sujeto, el mundo caído y antagonistico, el tercer reino poético, la realidad escondida que el poeta descubre en el objeto, la descripción de esencias y estructuras, la importancia de la metáfora y la destrucción artística de la realidad-, todo esto es lo que ha sido disfrazado tanto tiempo con las etiquetas de "poesía pura" y "deshumanización del arte". Tal vez podamos empezar a ver ya que estas cosas tienen más o menos tanto en común con Valéry y la poesía simbolista francesa como Pero Grullo con Monsieur Teste.

Philip Silver

State University of New York at Stony Brook.

22 A. DEL Río, Estudios sobre lit. esp. contemp., p. 209.

23 Amado Alonso, "Jorge Guillén, poeta esencial", en Materia y forma en poesía, $2^{*}$ ed., Madrid, 1960, p. 293. Este ensayo fue leído en un banquete que se ofreció a Guillén en 1929 para celebrar la aparición del primer Cántico. 